\title{
Role of Endothelial Nitric Oxide Synthase (T786C) Gene Polymorphism in the Development of Coronary Artery Disease
}

\author{
Deepak Tangadi ${ }^{1}$, Namrata Bhutani², Prabhash Bhavsar ${ }^{3}$ \\ ${ }^{1}$ Department of Biochemistry, Vardhman Mahavir Medical College \& Safdarjung Hospital, New Delhi, India. \\ ${ }^{2}$ Department of Biochemistry, Vardhman Mahavir Medical College \& Safdarjung Hospital, New Delhi, India. \\ ${ }^{3}$ Department of Biochemistry, Government Medical College, Dungarpur, Rajasthan, India.
}

\section{ABSTRACT}

\section{BACKGROUND}

Recent studies suggest a cause and effect relationship between eNOS gene polymorphism and increased incidence of insulin resistance as NO deficiency is associated with decreased vasodilation and altered binding of insulin to insulin receptor. Current studies suggest a worldwide association between eNOS-786T/C gene polymorphism and genetic susceptibility to insulin resistance. We wanted to study eNOS -786T/C gene polymorphism, nitric oxide and insulin Resistance in patients with CAD in Indian population.

\section{METHODS}

This study consisted of 60 cases who were adult patients with documented coronary artery disease. 60 age and sex matched healthy subjects were selected as controls. In these groups, fasting serum insulin was measured by ELISA, fasting serum nitric oxide by modified Griess reaction and fasting plasma glucose on fully automated chemistry analyser (Hitachi 902). Furthermore, HOMA-IR was calculated mathematically. The eNOS gene loci was amplified by using PCR and by RFLP. A pvalue $<0.05$ was considered significant. Statistical analysis was performed with SPSS.

\section{RESULTS}

The mean serum NO levels were very significantly lower in case groups and mean HOMA-IR levels in the study group were significantly higher as compared to the control group $(p=0.000)$ suggesting the role of insulin resistance in CAD. The frequency of Tallele was $76.67 \%$ in the study group and $81.67 \%$ in the control group while the frequency of Callele was $23.33 \%$ in the study group and $18.33 \%$ in the control group respectively. This difference was found to be statistically significant $(\mathrm{p}=0.0123)$.

\section{CONCLUSIONS}

Endothelial Nitric Oxide Synthase (T786C) gene polymorphism, is significantly associated with occurrence of coronary artery disease. Thus, this polymorphism could be a potential risk factor for development of coronary artery disease in adult Indian population.

\section{KEY WORDS}

Coronary Artery Disease, Nitric Oxide, Insulin Resistance, Polymorphism, RFLP
Corresponding Author:

Dr. Namrata Bhutani,

D-162, Tagore Garden Extn.,

New Delhi-110027,

India.

E-mail: namrata.bhutani@gmail.com

DOI: $10.14260 /$ jemds/2020/180

Financial or Other Competing Interests: None.

How to Cite This Article:

Tangadi D, Bhutani N, Bhavsar P. Role of endothelial nitric oxide synthase (T786C) gene polymorphism in the development of coronary artery disease. J. Evolution Med. Dent. Sci. 2020;9(11):833-837, DOI: 10.14260/jemds/2020/180

Submission 06-01-2020,

Peer Review 23-02-2020,

Acceptance 29-02-2020,

Published 16-03-2020.

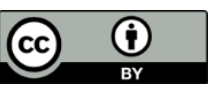




\section{BACKGROUND}

Coronary artery disease (CAD) has been labelled as a new age epidemic. By 2050, it is predicted to contribute to $34 \%$ of deaths in males and $32 \%$ of deaths in females in India. ${ }^{1}$ Current research suggests that majority of Coronary Artery Disease events are observed in individuals with at least one of the Coronary Artery Disease risk factors. ${ }^{2}$ Moreover, around 25 percent of coronary disease patients suffer from sudden death or myocardial infarction without any previous symptoms. ${ }^{3}$ Therefore, it is important to focus on the novel biomarkers that predict coronary risk. Also, it is known that endothelial dysfunction occurs due to cardiovascular risk factors and occurs prior to the development of atherosclerosis. Increase in prevalence of insulin resistance, Type 2 Diabetes Mellitus (T2D) and Coronary Artery Disease has been associated with an increase in western lifestyles and urbanization. ${ }^{4}$

The complex interaction between various genetic, environmental factors and life style modification factors are responsible for triggering insulin resistance and further development of T2D and Coronary Artery Disease. The precise cause and mechanism of Insulin resistance still remains to be elucidated and there is need to identify other causative risk factors and modify treatment. Nitric oxide (NO) is formed from L-arginine by a group of enzymes, Nitric oxide synthases (NOS), and is responsible for regulating the basal vascular tone. Apart from relaxing the vascular muscles, Nitric Oxide inhibits adhesion of platelet and leukocytes to vascular endothelium, it also inhibits the migration and growth of vascular smooth muscle cell, and controls the oxidation of atherogenic low density lipoprotein ${ }^{5}$. Studies on Endothelial Nitric Oxide Synthase (eNOS) knockout mice have demonstrated that decreased Nitric oxide synthesis contributes to the pathogenesis of coronary artery disease (CAD). ${ }^{6}$

Recent studies suggest a cause and effect relationship between eNOS gene polymorphism and increase incidence of insulin resistance as Nitric oxide deficiency is associated with decreased vasodilation and altered binding of insulin to insulin receptor resulting in diminished insulin-mediated vasodilation. However, several other studies have shown variable results. ${ }^{7}$ So, further research is needed to explore the exact relationship between eNOS -786T/C polymorphism and development of insulin resistance in patients with T2D with CAD. Recent studies worldwide suggest an association between eNOS -786T/C gene polymorphism and genetic susceptibility to insulin resistance. ${ }^{8}$ Data suggested NOS 786T/C gene polymorphism is distinct in specific population group, ethnicity and geographic region and perhaps this genetic variability might produce different results on exposure to various environmental factors. ${ }^{9}$ Besides there is hardly any data available in Indian population. ${ }^{10}$ So further research is needed to explore the complex interaction between environmental factors and eNOS -786T/C gene polymorphism in susceptibility to insulin resistance in patients with Coronary Artery Disease in Indian population. ${ }^{11}$ There is paucity of literature regarding association of eNOS gene (T786C) polymorphism and Insulin resistance in patients with Coronary Artery Disease in Indian population.

The studies associating NOS gene (T786C) polymorphism and risk of insulin resistance have yielded variable results. ${ }^{12}$
Hence the present study is planned to investigate the association of eNOS gene (T786C) polymorphism and Insulin resistance in patients with Coronary Artery Disease in Indian scenario.

This study aimed to study endothelial Nitric Oxide Synthase (T786C) gene polymorphism, Nitric oxide level and Insulin Resistance in patients with Coronary Artery Disease.

\section{METHODS}

The study was conducted in Department of Biochemistry and Department of Cardiology, Vardhman Mahavir Medical College and Safdarjung hospital, New Delhi. This was a hospital based case- control (observational) study conducted on patients attending Cardiac OPD in Safdarjung Hospital, New Delhi. The study population consisted of 60 adult patients of either sex with documented CAD. Consisted of 60 age and sex matched healthy subjects. All angiographically proven cases of coronary artery disease were included in the study.

\section{Exclusion Criteria}

1. Diagnosed cases of Type $1 \& 2$ Diabetes mellitus.

2. Patients with congenital heart diseases.

3. Chronic kidney and liver disease.

4. Any history of debilitating illness. Any history of drugs affecting NO levels.

The study was conducted after institutional Ethical Committee approval and informed consent was taken from all patients and controls. Bilingual in formed written consent was taken from the patients. Detailed clinical history with special reference to Coronary Artery Disease and thorough clinical examination of patient was conducted. Necessary anthropometric measurements like height, weight and body mass index were taken. Venous blood was collected from subjects under sterile conditions after overnight fasting. The whole blood collected in EDTA vacutainer was transferred to Eppendorf and Storedat-20 degree Celsius till DNA was extracted for PCR and RFLP. Nitric oxide in serum was determined indirectly by the measurement of its stable decomposition product nitrite $\left(\mathrm{NO}_{2}\right)$, by employing the Griess reaction according to the modified method of Mathew et al. ${ }^{13}$

\section{Estimation of Blood Glucose}

Blood Glucose estimation was done by Glucose oxidase peroxidase method using commercially available kit Randox GL 7952 on automated chemistry analyser Hitachi 902.

\section{HOMA-IR (Homeostasis Model of Assessment- Insulin Resistance)}

Insulin resistance was calculated mathematically by using formula given by Matthew et al. ${ }^{14}$ Fasting Glucose (mg/dl) $x$ fasting Insulin $(\mu \mathrm{U} / \mathrm{mL}) / 405$ Manual DNA extraction by the method of Daly's et al. ${ }^{15}$

\section{Polymerase Chain Reaction (PCR) Amplification}

The required region of NOS3 gene from genomic DNA was amplified by Polymerase Chain Reaction in MJ Research PTC$100^{\mathrm{TM}}$ (Peltier Thermal Cycler). 


\section{Primer Sequence for NOS3}

Forward Primer: 5' - GTCTCTCAGCTTCCGTTTCTT-3'

Reverse Primer: 5' - CCTTGAGTCTGACATTAGGGTATC-3'

These primers were used to amplify a458bp product for $\mathrm{T}$ 786C (rs2070744)

\section{Reagents Required}

1. Template DNA (e.g. genomic DNA): 200-300ng

2. Forward and reverse PCR primers (active oligos): $0.3 \mathrm{pM}$

3. $\mathrm{MgCl}_{2}$ (present in PCR Buffer): $20 \mathrm{mM}$

4. dNTPs (a mixture of dATP, dCTP, dGTP, and dTTP): (Thermo Fischer Scientific)

5. 10× PCR buffer (Thermo Fischer Scientific): $200 \mu \mathrm{M}$

6. TaqDNA polymerase (Dream Taq, Thermo Fischer Scientific): $1 \mathrm{X}$

7. Water to make total volume up to $20 \mu \mathrm{l}: 0.3 \mathrm{pM}$

The thermal cycling conditions were carried out in a PTC$100^{\mathrm{TM}}$ (Peltier Thermal Cycler) machine as followsDenaturation at $95^{\circ} \mathrm{C}$ for $2 \mathrm{~min}, 30$ cycles of denaturation at $9^{\circ} \mathrm{C}$ for $30 \mathrm{sec}$, annealing at $58^{\circ} \mathrm{C}$ for $30 \mathrm{sec}$, elongation at $72^{\circ} \mathrm{C}$ for $90 \mathrm{sec}$, followed by a final elongation step at $72^{\circ} \mathrm{C}$ for $10 \mathrm{~min}$. The PCR products were analysed in a $2 \%$ agarose gel in a $1 \mathrm{X}$ TAE buffer system. This product was digested with restriction enzyme separately to reveal the genotype for the SNP.

\section{Condition for Digestion}

The PCR product $(10 \mu \mathrm{l})$ was digested individually with $1 \mu \mathrm{l}$ (10 unit/ $\mu \mathrm{l}$ ) of Msp1 (Krishgen) with $2 \mu \mathrm{l}$ of 10x restriction buffer and $18 \mu \mathrm{l}$ of nuclease free water incubated at $37^{\circ} \mathrm{C}$ for 16 hours. Digested product was analysed in a $2 \%$ agarose gel. The TT genotype produced two fragments of 303bp and $155 \mathrm{bp}$, while TC genotype produced three fragments of 257bp, 155bp and 46bp.

\section{Statistical Analysis}

A p-value $<0.05$ was considered significant. Statistical analysis was performed with the help of SPSS version 20. The data was subjected to t-test \& dichotomous variables and allele frequencies were analysed by Chi-Square test. For correlation of two continuous variables, correlation coefficient was used.

\section{RESULTS}

The study population consisted of $56.66 \%$ males and $43.33 \%$ females whereas the control group consisted of $60 \%$ males and $40 \%$ females. The mean HOMA-IR was higher in the cases $(2.46 \pm 1.16)$ as compared to the controls $(1.63 \pm 0.69)$, with statistically significant difference $(p=0.000)$. Endothelial Nitric Oxide (eNOS) gene variants (T786-C) was determined in both groups. TT genotype was found in 32 subjects in the study group (53.33\%) and in 38 subjects in the control group (63.33\%), whereas the TC genotype was found in 28 subjects in the study group (46.66\%) and in 22 subjects in the control group (36.66\%) respectively. No CCgeno type was found in any group. The genotype distribution was in Hardy Weinberg equilibrium. The frequency of Tallele was $76.67 \%$ in the study group and $81.67 \%$ in the control group while the frequency of Callele was $23.33 \%$ in the study group $18.33 \%$ in the control group respectively. This difference was found to be statistically significant. ( $p=0.0123$, table 3 ).

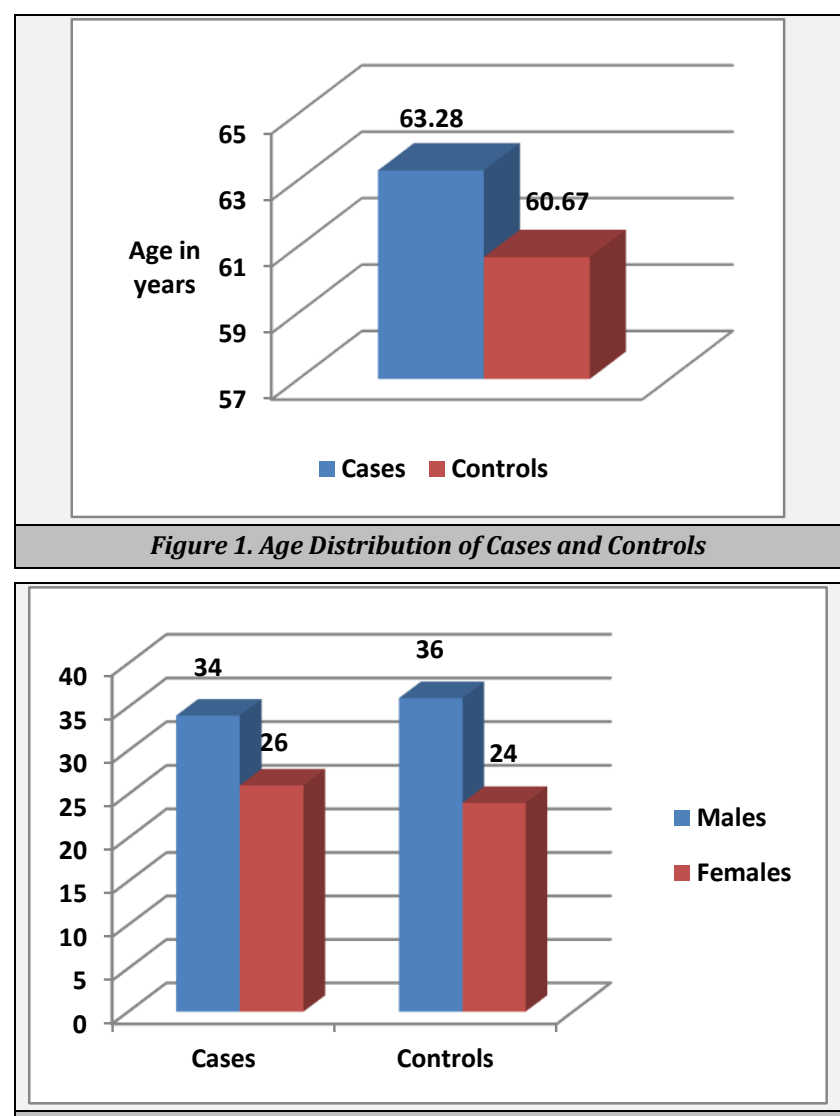

Figure 2. Gender Distribution of Cases and Controls

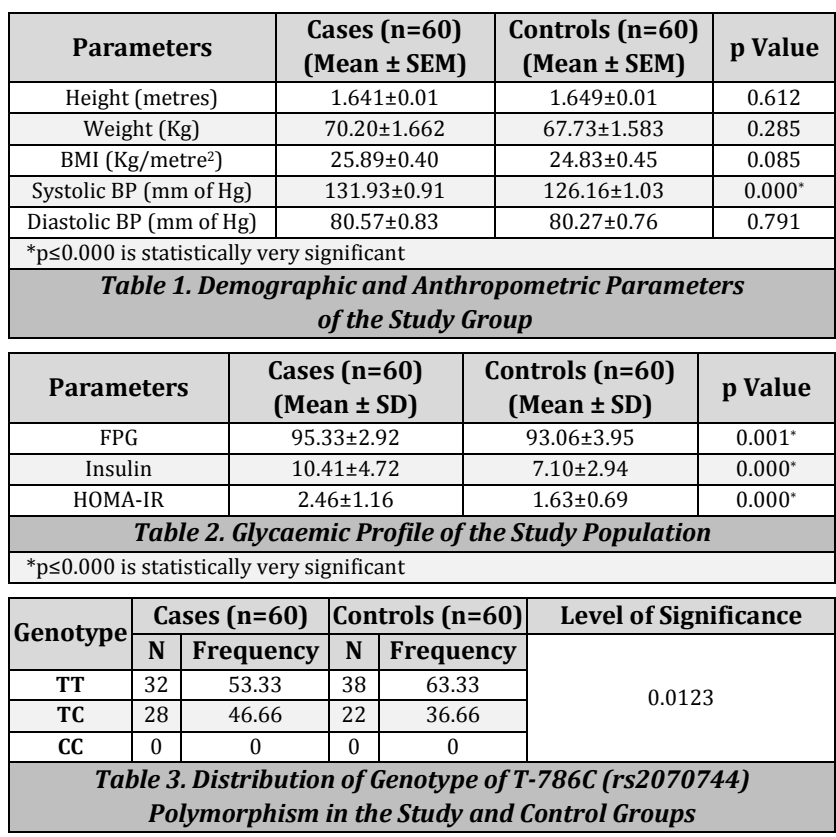

\section{DISCUSSION}

The effect of endothelial nitric oxide synthase gene polymorphism on Insulin resistance has not been widely reported up till now. In the present study we have evaluated the effect of endothelial nitric oxide synthase gene polymorphism (assessed by RFLP and nitric oxide levels) on 
insulin resistance (calculated by HOMA-IR) in patients of Coronary Artery Disease. ${ }^{16-18}$

In our study we found that the mean systolic blood pressure was higher in the cases $131.93 \pm 0.91 \mathrm{~mm}$ of $\mathrm{Hg}$ as compared to the controls $126.16 \pm 1.03 \mathrm{~mm}$ of $\mathrm{Hg}$, with statistically very significant difference $(p=0.000)$. Our findings are similar to the study done by Garg and colleagues. ${ }^{19-21}$ The probable reason for high BP in these patients is insulin resistance and the resultant hyper insulinemia which increases BP by activation of the sympathetic nervous system and rennin-angiotensinaldosterone system (RAAS) resulting in sodium retention and volume expansion. ${ }^{22}$ Activation of RAAS produces angiotensin II which acts through angiotensin I receptors, thus inhibits the vasodilatory effects of insulin on blood vessels and increasing BP. Hyperinsulinemia in insulin resistant state also stimulates the mitogen-activated protein kinase (MAPK) pathway, which promotes vascular injury.

NO can be seen in majority of the tissues and cells of the body and it has an important role in modulating vascular tone and hemodynamic status. It also promotes endothelial proliferation and angiogenesis, thus it has an essential role in modulating microcirculation. Moreover, it also inhibits the release of, a vasoconstrictor, endothelin-1. It also plays a role in cardiovascular system including regulation of blood pressure, thrombocyte aggregation inhibition, leukocyte adhesion, smooth muscle cell proliferation, and oxidation of LDL. in this study, the mean plasma nitric oxide level in the study group cases was $17.80 \pm 0.95 \mu \mathrm{M} / \mathrm{L}$ and in the control group was $22.47 \pm 0.83 \mu \mathrm{M} / \mathrm{L}$. The difference between the two was statistically significant $(p=0.000)$. The decrease in production in patients are associated with events that accelerate development of atherosclerosis such as vasoconstriction, thrombocyte aggregation, migration of monocytes to the vascular wall, oxidized LDL and foam cell production.

Our study is in accordance with studies by Flammeretal ${ }^{23}$ and Luscher et $\mathrm{al}^{24}$ who have postulated that Low levels of NO in patients is suggestive that patients are more likely to have accelerated development of atherosclerosis. In our study we found that the markers of insulin resistance were significantly raised in cases as compared to controls. The mean HOMA-IR levels in the study group was $2.46 \pm 0.15$ and in the control group was $1.63 \pm 0.09$. The difference between the two groups was very significant $(p=0.000)$. The mean serum insulin levels in the study group were $10.41 \pm 0.61$ $\mu \mathrm{IU} / \mathrm{mL}$ and in the control group were $7.10 \pm 0.38 \mu \mathrm{IU} / \mathrm{mL}$ and the difference between the two groups was statistically very significant $(\mathrm{p}=0.000)$.

Bertoluci et $\mathrm{al}^{25}$ suggested that increased HOMA-IR is positively associated with angiographic Coronary Artery Disease and may be useful for risk stratification as a high specificity test for Coronary Artery Disease. The probable reason for increased cardiovascular risk in patients with insulin resistance is that insulin resistance in adipocytes leads to reduced uptake of circulating lipids and increased hydrolysis of stored triglycerides. Increased mobilization of stored lipids from these cells would elevate free fatty acids in blood thereby causing dyslipidaemia, which would predispose the patient to increased cardiovascular risk. Other studies have also proposed that insulin resistance accentuates the risk of CAD. Our findings suggest that TT genotype may have a protective role in development of insulin resistance and coronary artery disease as seen by increased frequency of TT genotypes than TC genotypes in case as compared to control groups. These findings are similar to findings of previous studies. ${ }^{25}$ However, these findings need to be confirmed in a larger sample size.

\section{CONCLUSIONS}

Reduced plasma level of nitric oxide is associated with increased risk of CAD. Also, higher HOMA-IR levels are found in patients with CAD. Moreover, endothelial Nitric Oxide Synthase (T786C) gene polymorphism, is a significant risk factor for development of CAD.

\section{REFERENCES}

[1] WHO Cardiovascular diseases (CVDs). World Health Organization; [cited 2015 Apr 19]. http://www.who.int/mediacentre/factsheets/fs317/en/

[2] What Are Coronary Heart Disease Risk Factors? - NHLBI, NIH [cited 2015 Apr https://www.nhlbi.nih.gov/health/healthtopics/topics/hd

[3] Goyal A, Yusuf S. The burden of cardiovascular disease in the Indian subcontinent. Indian J Med Res 2006;124(3):235-44.

[4] Hadi HA, Al Suwaidi. Endothelial dysfunction in diabetes mellitus. Vasc Health Risk Manag 2007;3(6):853-76.

[5] Ray S, Bairagi AK, Guha S, et al. A simple way to identify insulin resistance in non-diabetic acute coronary syndrome patients with impaired fasting glucose. Indian J Endocrinol Metab 2012;16(Suppl 2):S460-4.

[6] Vecoli C, Andreassi MG, Liga R, et al. T(-786) $\rightarrow C$ polymorphism of the endothelial nitric oxide synthase gene is associated with insulin resistance in patients with ischemic or non ischemic cardiomyopathy. BMC Med Genet 2012;13(1):92.

[7] Samant P, Chavan P, Rai S. Association of eNOS gene variant with insulin resistance in Metabolic Syndrome Material \& Methods 2014;2(6):784-91.

[8] Duplain H, Burcelin R, Sartori C, et al. Insulin resistance, hyperlipidemia and hypertension in mice lacking endothelial nitric oxide synthase. Circulation 2001;104(3):342-5.

[9] Mathers CD, Loncar D. Projections of global mortality and burden of disease from 2002 to 2030. PLoS Med 2006;3(11):e442.

[10] WHO. The global burden of disease: 2004 update. World Health Organization; [cited 2015 Apr 28]. http://www.who.int/healthinfo/global_burden_disease/ 2004_report_update/en/

[11] Lloyd-Jones D, Adams R, Carnethon M, et al. Heart disease and stroke statistics--2009 update: a report from the American Heart Association Statistics Committee and Stroke Statistics Subcommittee. Circulation 2009;119(3):e21-81. 
[12] Coronary artery disease management: to relieve symptoms and reduce the risk of cardiovascular events | CLARIFY registry official web site [cited 2015 Apr 28]. http://www.clarify-registry.com/journalists/aboutcoronary-artery-disease/4-coronary-artery-diseasemanagement/

[13] World Health Organization. a Vital Investment. World Health, 2005: p. 202.

[14] Beaglehole R, Bonita R. Global public health: a scorecard. Lancet 2008;372(9654):1988-96.

[15] WHO. Burden of disease: DALYs. Glob Burd Dis 2004 Updat. 2008: p. 40-51.

[16] Jones DW, Chambless LE, Folsom AR, et al. Risk factors for coronary heart disease in african americans: The Atherosclerosis Risk in Communities Study, 1987-1997. Arch Intern Med 2002;162(22):2565-71.

[17] Tendera M. How much does Europe invest in the treatment of cardiovascular diseases? Eur Heart J 2006;27(13):1521-2.

[18] Yoshimura T, Hisatomi A, Kajihara S, et al. The relationship between insulin resistance and polymorphisms of the endothelial nitric oxide synthase gene in patients with coronary artery disease. J Atheroscler Thromb 2003;10(1):43-7.

[19] Fox KA. Implications of the organization to assess strategies for ischemic syndromes-2 (OASIS-2) study and the results in the context of other trials. Am J Cardio 1999;84(5A):26M-31M.
[20] Mohan V, Venkatraman JV, Pradeepa R. Epidemiology of cardiovascular disease in type 2 diabetes: the Indian scenario. J Diabetes Sci Technol 2010;4(1):158-70.

[21] Okita K, Iwahashi H, Kozawa J, et al. Homeostasis model assessment of insulin resistance for evaluating insulin sensitivity in patients with type 2 diabetes on insulin therapy. Endocr J 2013;60(3):283-90.

[22] Kontos MC, Diercks DB, Kirk JD. Emergency department and office-based evaluation of patients with chest pain. Mayo Clin Proc 2010;85(3):284-99.

[23] Lee IM, Shiroma EJ, Lobelo F, et al. Effect of physical inactivity on major non-communicable diseases worldwide: an analysis of burden of disease and life expectancy. Lancet 2012;380(9838):219-29.

[24] Kivimäki M, Nyberg ST, Batty GD, et al. Job strain as a risk factor for coronary heart disease: a collaborative meta-analysis of individual participant data. Lancet 2012;380(9852):1491-7.

[25] Wang HX, Leineweber C, Kirkeeide R, et al. Psychosocial stress and atherosclerosis: family and work stress accelerate progression of coronary disease in women. The Stockholm Female Coronary Angiography Study J Intern Med 2007;261(3):245-54. 